\title{
Effect of Increasing Load on WLAN Analyzed Through OPNET Simulator
}

\author{
Manoj Tolani \\ Research Scholar \\ Electronics and communication (Digital Systems) \\ Madan Mohan Malaviya \\ Engineering College, Gorakhpur
}

\author{
Rajan Mishra \\ Assistant Professor \\ Electronics and communication (Digital Systems) \\ Madan Mohan Malaviya \\ Engineering College, Gorakhpur
}

\begin{abstract}
Wireless LAN has very important property of LAN sharing make it advantageous in Ad-Hoc networks. In WLAN each node has Wi-Fi capability. In this paper we are analyzing such a WLAN network in which we increase load by increasing traffic and analyze the effect of increasing traffic, we also analyze the network for different routing protocols and check performance of which routing protocol not degraded on increasing load means which routing protocol is less sensitive to load.
\end{abstract}

\section{Keywords}

\section{WLAN, LOAD, AODV, OLSR \& TORA}

\section{INTRODUCTION}

Wireless network is a type of computer network in which nodes are interconnected with each other without wires. These nodes have Wi-Fi capability, Wi-Fi stands for wireless fidelity. IEEE $802.11 \mathrm{Wi}-\mathrm{Fi}$ is a type of computer to computer connection as in a LAN without need of wire. We can increase the load on WLAN by two ways. In first case we increase the load on server node by increasing the number of nodes and second by increasing the traffic (means we apply heavy traffic by each node). When increasing the load cause increase the collision of packets which cause more data dropped and finally throughput reduces and so that wastage of channel. We analyze the network in both cases and for all three routing protocols. We take two configurations, first configuration is application configuration and other is profile configuration. In a profile we set multiuser profile and in application we set two different application video conferencing and voice application (PCM). In third case we apply FTP Traffic for analysis.

\section{WLAN PARAMETERS}

There are number of WLAN parameters on which wireless LAN performance is affected. In this section we discuss various WLAN parameters. We are not analyzing network for mobility profile and terrain profile. As shown in Fig BSS set to be auto assigned in this case all the nodes are belong to same BSS, if in a BSS any node need to communicate with other node that belongs to any other BSS than we need to set access point functionality enabled otherwise it is not capable to communicate with node that belongs to other BSS. We set access point functionality disabled because all the nodes belong to the same BSS. We set direct sequence technique and 11 Mbps data rate. All other WLAN parameters are default set as shown in Fig 1.

Table 1: WLAN parameters for analyzed network

\begin{tabular}{|c|c|}
\hline \multicolumn{2}{|c|}{ SIMULATION PARAMETERS } \\
\hline No. Of Nodes & 52 \\
\hline Playground size & $440 \mathrm{~m} * 230 \mathrm{~m}$ \\
\hline Simulation time & $600 \mathrm{sec}$ \\
\hline \multicolumn{2}{|c|}{ ROUTING MAC PROTOCOL } \\
\hline Routing Protocol & AODV,OLSR,TORA \\
\hline MAC Protocol & $802.11 \mathrm{~g}$ \\
\hline Data Rate & $11 \mathrm{Mbps}$ \\
\hline \multicolumn{2}{|c|}{ RADIO CHARACTERISTICS } \\
\hline Transmitted Power & $5 \mathrm{~mW}$ \\
\hline $\begin{array}{l}\text { Packet Reception } \\
\text { Power Threshold }\end{array}$ & $-95 \mathrm{dBm}$ \\
\hline BSS & Auto assigned \\
\hline
\end{tabular}

\section{PERFORMANCE ANALYSIS}

We analyze the WLAN network for 3 cases and for each case there are three scenarios for three routing protocols AODV, OLSR and TORA. We increase the load and compare the performance for two important parameters throughput and delay.

\section{First case (normal case)}

In this case we take 12 WLAN network and 1 server node. Server node is capable to support all types of services (such as video conferencing, FTP etc). For each node we set multiuser profile, in multiuser profile there are two types of applications video conferencing and voice application (PCM). We analyze this network for three routing protocols AODV, OLSR and TORA respectively scenarios $1,2 \& 3$. WLAN network is shown in Fig 1. 


\subsection{Second case (Load increases by increasing number of nodes)}

Nodes are increases to increase the load on server and analyze the network. Now there are 20 nodes and each node having multimedia profile. Further we analyze this network for all three routing protocols AODV, OLSR \& TORA. WLAN network is shown in Fig 2.

\subsection{Third case (Load increases by increasing the traffic generated by each node)}

In this case we take 12 nodes as taken earlier but FTP traffic with $2 \mathrm{sec}$ inter-arrival time and now we generate more traffic by applying FTP traffic of $0.2 \mathrm{sec} \& 0.02 \mathrm{sec}$ on application profile. This generates more traffic and so that load on server node increases. We analyze this network for three different routing protocols. WLAN network is shown in Fig 1.

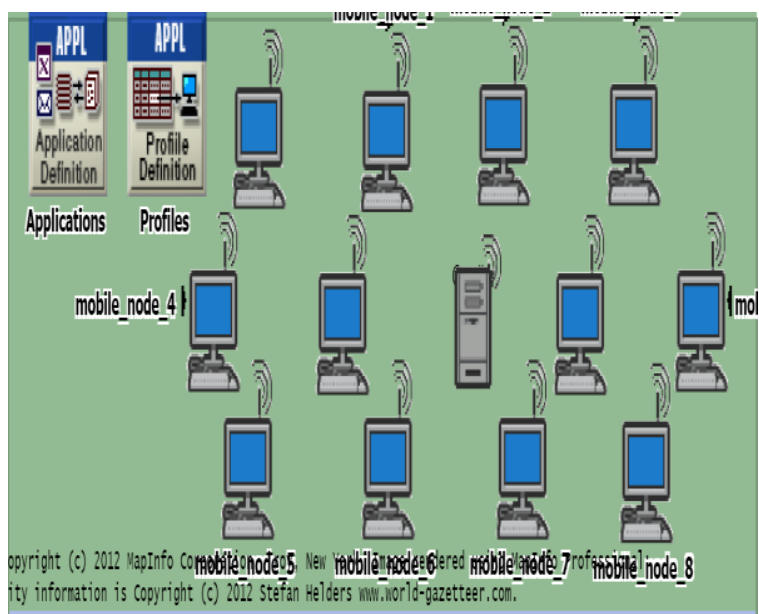

Fig 1: 12 nodes WLAN network in first case \& third case

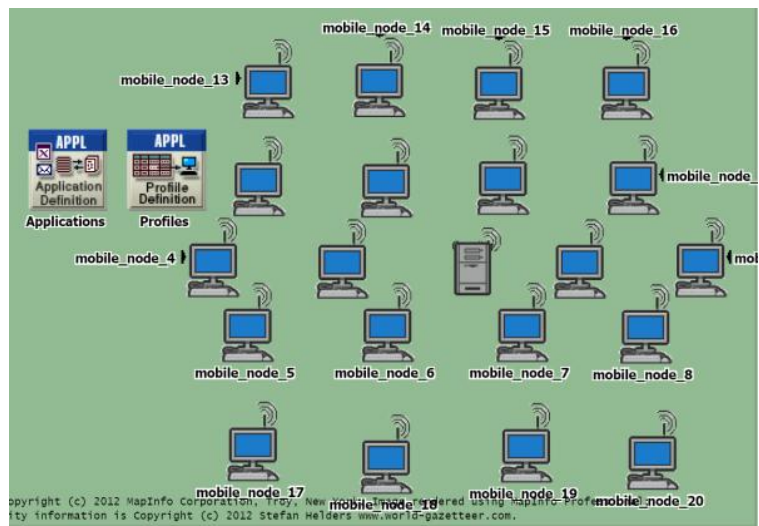

Fig 2:20 node WLAN network in second case

\section{SIMULATION RESULTS}

By the simulation of these scenarios we get different results and comparing these results we get that as we increase the number of nodes more packet collision take place and data dropped so that throughput reduces and delay increases. When we increase the traffic by increasing number of nodes throughput reduces, delay increases and data dropped increases for AODV, OLSR, and TORA as shown in Fig 3 to Fig 10.

\begin{tabular}{|l|l|}
\hline 12 node & 20 node \\
\hline & \\
\hline
\end{tabular}

Fig 3: color code for Fig 4, 5, 6,7, 8, 9, 10

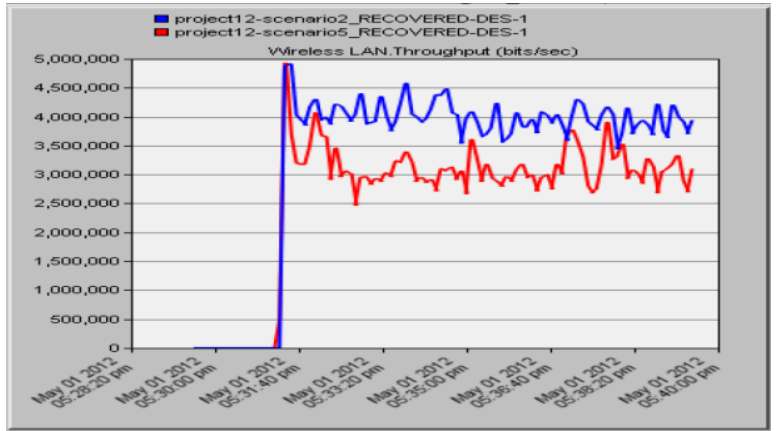

Fig 4: Throughput comparison of 12 node $\& 20$ nodes WLAN network for AODV

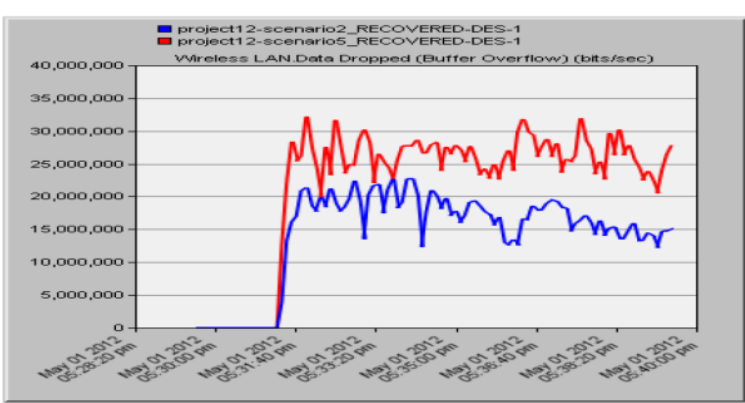

Fig 5: Data dropped comparison of 12 node \& 20 node WLAN network for AODV

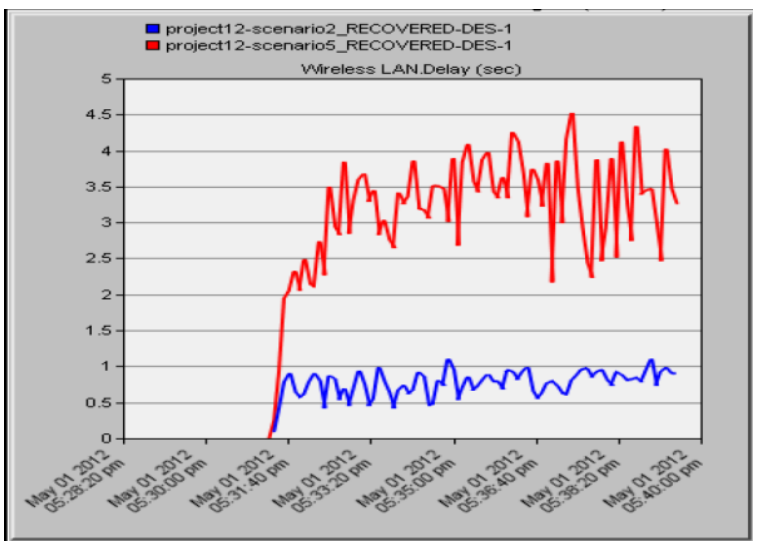

Fig 6: Delay comparison of 12 node $\& 20$ node WLAN network for AODV

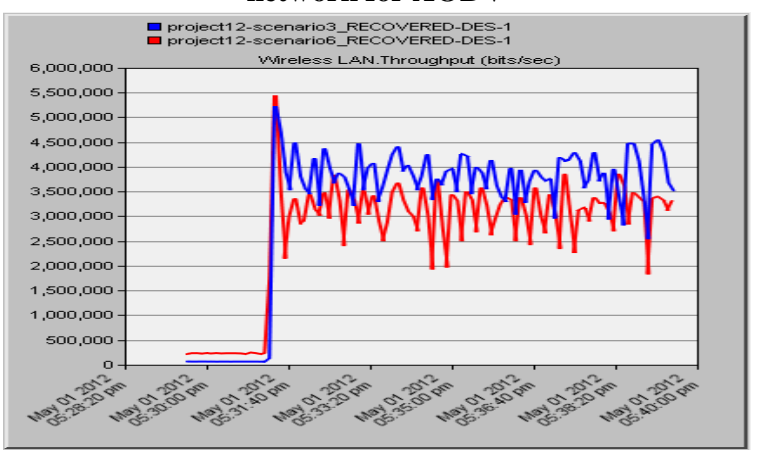

Fig 7: Throughput comparison of 12 node $\& 20$ node WLAN network for OLSR 


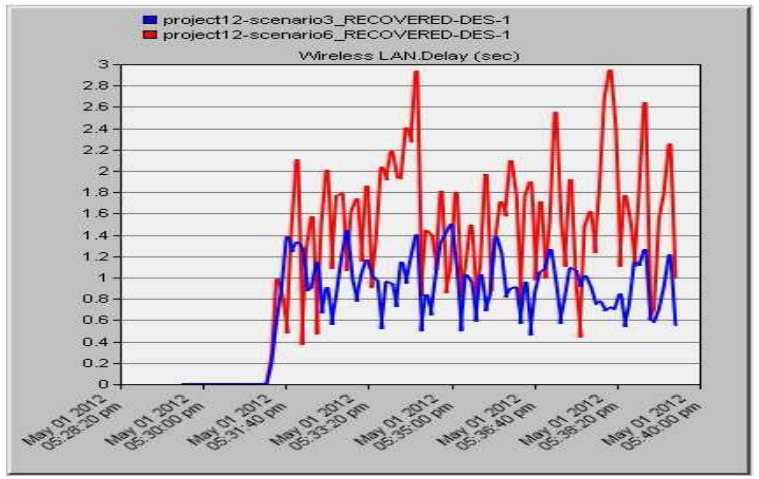

Fig 8: Delay comparison of 12 node $\& 20$ node WLAN network for OLSR

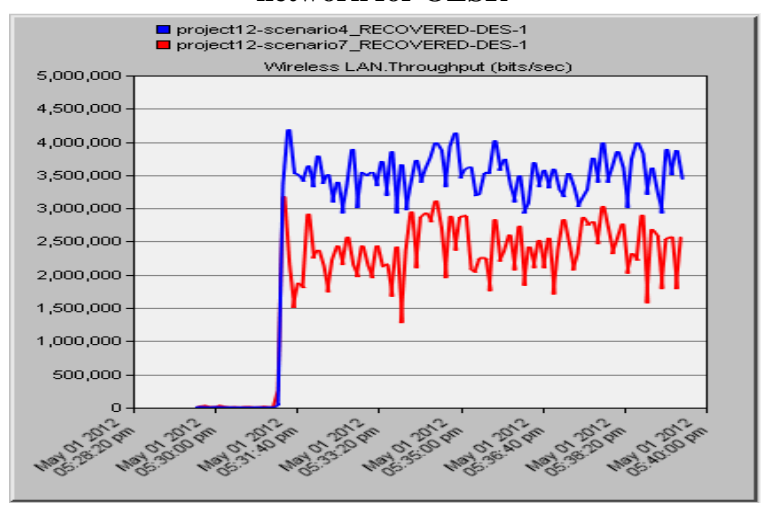

Fig 9: Throughput comparison of 12 node $\& 20$ node WLAN network for TORA

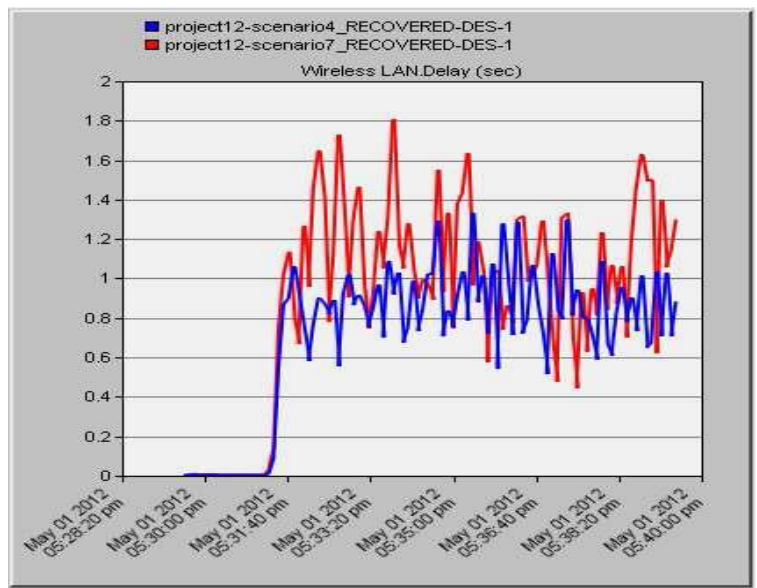

Fig 10: Delay comparison of 12 node \& 20 node WLAN network for TORA

\begin{tabular}{|c|c|c|}
\hline $\begin{array}{c}\text { Normal traffic } \\
\text { Inter-arrival } \\
\text { time } 2 \mathrm{sec}\end{array}$ & $\begin{array}{c}\text { Increased traffic } \\
\text { Inter-arrival time }\end{array}$ & $\begin{array}{c}\text { Increased traffic } \\
\text { Inter-arrival } \\
\text { time } 0.2 \mathrm{sec}\end{array}$ \\
\hline & $0.2 \mathrm{sec}$ & \\
\hline
\end{tabular}

Fig 11: color code for Fig 12, 13, 14, 15, 16, 17

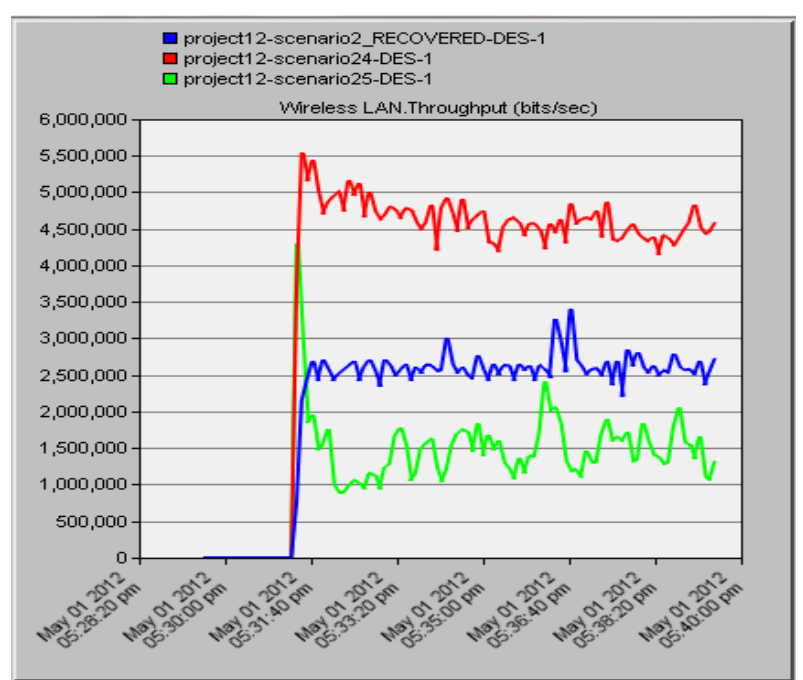

Fig 12: Throughput comparison of 12 nodes WLAN when traffic increases by each node for AODV

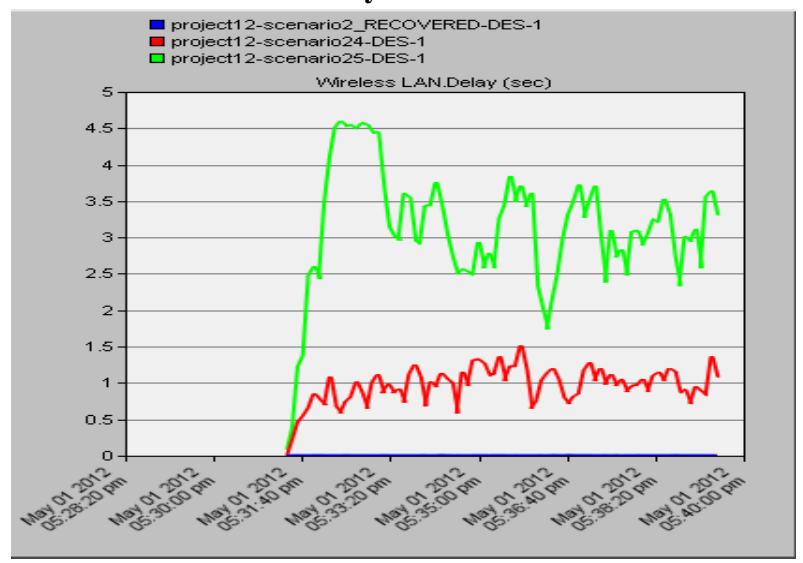

Fig 13: Delay comparison of 12 nodes WLAN when traffic increases by each node for AODV

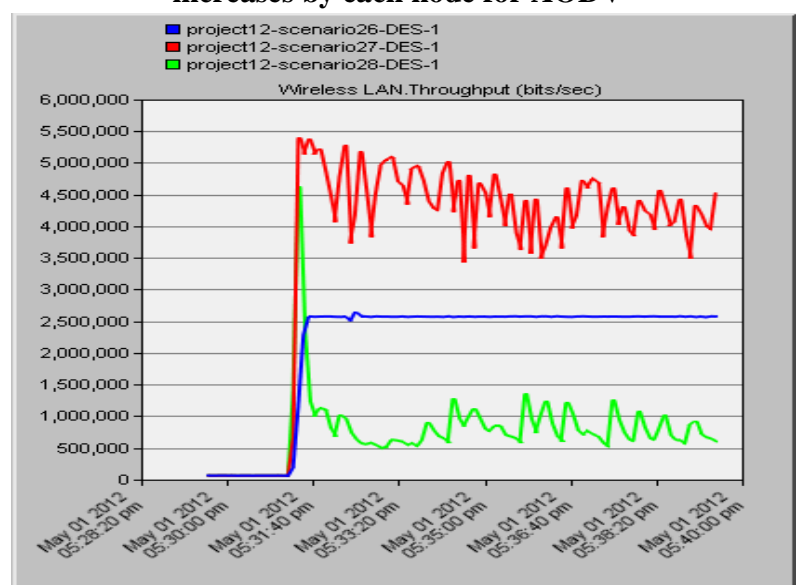

Fig 14: Throughput comparison of 12 nodes WLAN when traffic increases by each node for OLSR 


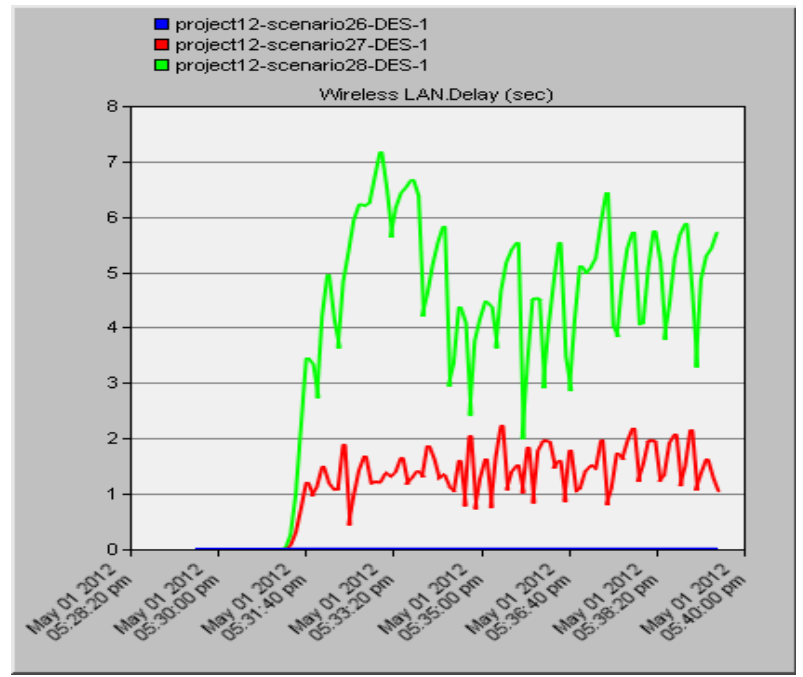

Fig 15: Delay comparison of 12 nodes WLAN when traffic increases by each node for OLSR

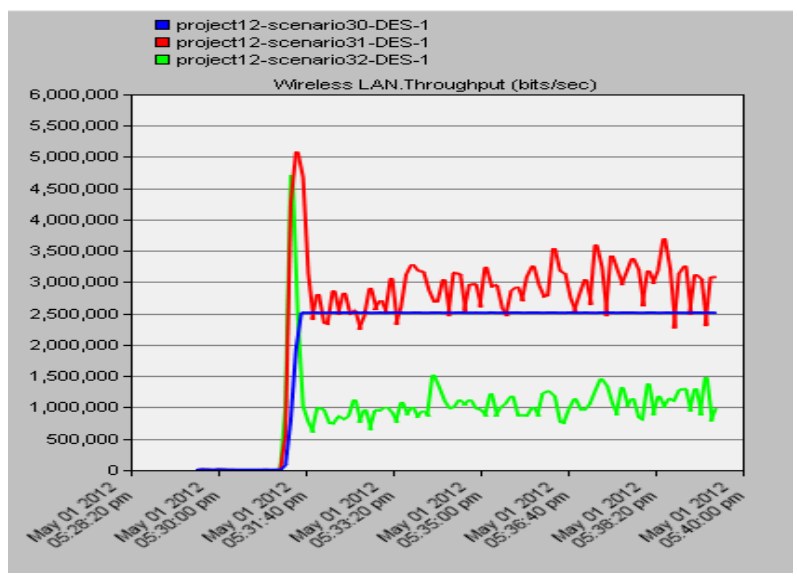

Fig 16: Throughput comparison of 12 nodes WLAN when traffic increases by each node for TORA

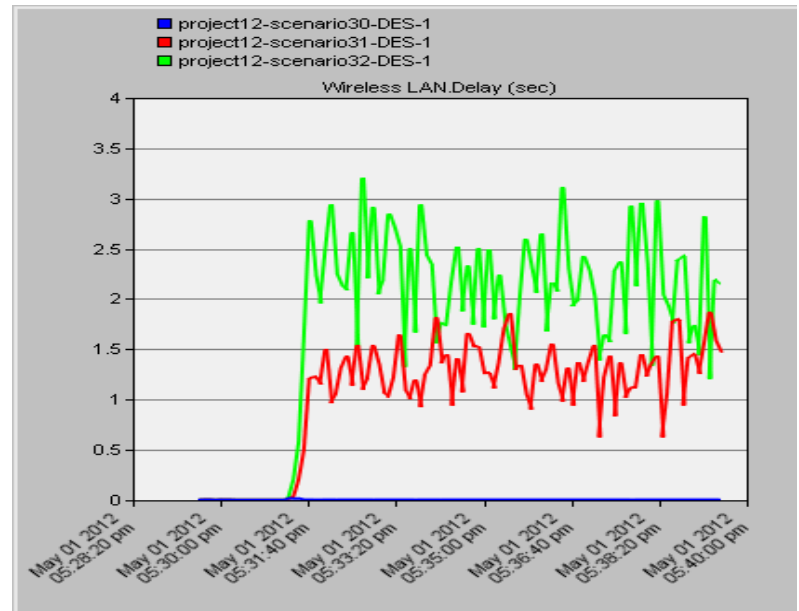

Fig 17: Delay comparison of 12 nodes WLAN when traffic increases by each node for TORA

From the Figures it is clear that as number of nodes increases throughput of AODV and TORA are more effected as compared to OLSR. Now we increase FTP traffic in third case by varying inter-arrival time $2 \mathrm{sec}$ to $0.2 \mathrm{sec} \&$ then $0.02 \mathrm{sec}$. Due to increase in traffic from $2 \mathrm{sec}$ to $0.2 \mathrm{sec}$ inter-arrival time throughput increases but more increase in traffic cause reduction in throughput because channel becomes congested
\& so increase in collision count. In all cases delay increases when increase in traffic take place as shown in Fig 11 to Fig 17.

\section{SIMULATION SOFTWARE}

We are using 14.5 version of OPNET simulator, OPNET stands for optimized network simulator which is advanced software for this generation. It is also supported windows and easy to design the network because it support GUI (Graphical User Interface).

\section{CONCLUSION AND FUTURE WORK}

From the above analysis it is clear that as the when load increases by increasing number of nodes throughput reduces and delay increases. Similarly when load increases by increasing data traffic of each node throughput increases but if we increase more traffic its performance degrades due to increase in collision count and so throughput reduce. Due to increase in traffic data dropped due to buffer overflow also increases and so that delay also increases. When traffic increases more packet collision take place and so that performance degrades. From the results it is also clear that OLSR having lesser delay. In terms of throughput AODV \& OLSR perform better with respect to TORA. In future we try to design new routing protocol whose performance will not effected to much by increasing traffic load because due to large traffic much of the information lost.

\section{ACKNOWLEDGEMENTS}

The authors would like to thank OPNET for modeling tool support through their OPNET University Program.

\section{REFERENCES}

[1] Patrick Sondi, DhavyGantsou and Sylvain Lecomte, "Mobile Ad Hoc Network-Based Monitoring Of Battlefields Or Rescue Operations In Urban Scenarios", UKSim Fourth European Modelling Symposium on Computer Modelling and Simulation, pages pp 408-413, IEEE 2010.

[2] Zahian Ismail, Rosilah Hassan, "Effects Of Packet Size On AODV Routing Protocol Implementation In Homogeneous And Heterogeneous MANET", 2011 Third International Conference on Computational Intelligence, Modelling\& Simulation, pages pp 351-356, IEEE 2011.

[3] MostafaFazeli, HasanVaziri, “Assessment Of Throughput Performance Under OPNET Modeler Simulation Tools In Mobile Ad Hoc Networks (MANET's)", 2011 Third International Conference on Computational Intelligence, Communication Systems and Networks,pages pp 328-331, IEEE 2011.

[4] AshishShrestha, FiratTekiner, "On MANET Routing Protocols for Mobility and Scalability" 2009 International Conference on Parallel and Distributed Computing, Applications and Technologies, pages pp 451-456, IEEE 2009.

[5] R.K.Nadesh , D.Sumathy, M. B. BenjulaAnbu Malar, "Performance Analysis Of MANET (WLAN) Using Different Routing Protocols In Multi Service Environments-An Quantitative Study", Int. J. Advanced Networking and Applications Volume: 03, Issue: 02, Pages:1076-1079 (2011)

[6] Anuj K. Gupta, Member, IACSIT, Dr. Harsh Sadawarti, Dr. Anil K. Verma, "Performance Analysis Of AODV, 
DSR \& TORA Routing Protocols", IACSIT International Journal of Engineering and Technology, Vol.2, No.2,pages pp 226-231 April 2010.

[7] Al-Maashri, A. and Ould-Khaoua, M. (2006) "Performance Analysis Of MANET Routing Protocols in the presence of Self-Similar Traffic", Proceedings of the 31st IEEE Conference on Local Computer Networks,2006, 14-16 November 2006, pages pp. 801807, Tampa, Florida, USA.

[8] Yi Wang, Hairong Chen, Xinyu Yang and Deyun Zhang, "Cluster Based Location-Aware Routing Protocol For Large Scale Heterogeneous Manet", Second International Multisymposium on Computer and Computational Science, Computer Society pages pp 366-373, IEEE (2007)

[9] EmadAboelela, "Computer Networks A System Approach, Edition-3, Networks Simulation Experiment Mannual", University of Massachusetts Dartmouth, 2003.

[10] TanviMalik,Gaurav Mittal, Monika Aggarwal "Simulation Based Performance Analysis of Ad-Hoc Routing Protocols in Various Moving Trajectories", Department of ECE, B.G.IET, Sangrur, India, Vol 1, Issue 7, 373-375, IJCSET August 2011

[11] Theodore S.Rappaport "Wireless Communications Principles and Practice" pearson publication, second edition, 2010.

[12] Jochen Schiller "Mobile Communications" Pearson publication, second edition, 2009.
[13] Dharma Prakash Agarwal, Qing-An zeng "Introduction to wireless and mobile systems" THOMSON Vikas publishing House, 2003.

[14] Ashish Shrestha, Firat Tekiner, "On MANET Routing Protocols for Mobility and Scalability", International Conference on Parallel and Distributed Computing, Applications and Technologies, 2009, pages pp. 451-456, IEEE, 2009.

[15] Beauchamp, K. G.; "Computer Communications - 2nd ed." - Chapman and Hall, 1990. - 0412370700

[16] Manoj Tolani, Rajan Mishra, "performance analysis of wlan by comparative study of various attributes using opnet simulator" International Journal of Scientific \& Engineering Research, Volume 3, Issue 6, June-2012 ISSN 2229-551, pages pp 1-4.

[17] Manoj Tolani, Rajan Mishra, "Simulation Based Comparison of Fixed Ad-Hoc Network and Mobile AdHoc Network by Varying Internode Distance", VSRDIJEECE, Vol. 2 (5), 2012,pages pp- 201-206.

[18] Loay Abusalah, Ashfaq Khokhar, and Mohsen Guizani A Survey of Secure Mobile Ad Hoc Routing Protocols, IEEE COMMUNICATIONS SURVEYS \& TUTORIALS, VOL. 10, NO. 4, FOURTH QUARTER 2008.

[19] Luc Hogie; Pascal Bouvry; Frederic Guinand - "An Overview of MANETs Simulation”; Elsevier B.V.; 2006. 